\title{
Os arquivos na intersecção de campos de conhecimentos diferentes
}

The archives at the intersection of different fields of knowledge

\author{
Giulia Crippa \\ Livre Docente em Ciência da Informação pela FFCLRP/USP \\ Professora Associada do Curso de Biblioteconomia, Ciências da Informação e da Documentação da \\ FFCLRP/USP \\ E-mail: giuliac@ffclrp.usp.br
}

BALDACCI, Cristina. Archivi impossibili: un'ossessione dell'arte contemporanea.

Cremona: Johan \& Levi, 2016.

Há algumas décadas, um dos lugares de catalogação e preservação mais antigos e estáveis em suas definições e conceitos, o arquivo, está no centro de discussões e mudanças que investem desde seus materiais como, de maneira mais teóricas, suas próprias funções. Se, de fato, o arquivo, desde sua origem na antiguidade, nasce "maduro" - na medida em que é o lugar em que se guardam materiais que se chamam documentos e que desempenham funções práticas ligadas à administração - é também verdade que ele tem sido alvo de atenções artísticas voltadas para a acumulação de informações, a organização e exposição de objetos, a produção de listas e inventários, oferecendo, assim, novas perspectivas na reflexão sobre sua própria conceitualização.

A memória do arquivo existe na forma de documentos, mapas, textos literários, cartas, resto arqueológicos, vídeos, filmes, CDs, enfim, itens resistentes à mudança. Arquivo vem do grego, referindo-se etimologicamente a um edifício público em que se guardam registros, provindo de arkhé, que significa também começo, primeiro lugar, o governo. O arquivo, assim, sustenta desde o começo o poder. A memoria de arquivo trabalha a distância, acima e além de tempo e espaço, como uma "máquina do tempo" que permite idas e voltas ao/do passado. O fato de a memória de arquivo separar a fonte do conhecimento daqueles que conhecem, ou seja, de ser observado em si como espelho (ainda que deformado e deformante) de sua entidade produtora, leva autores como de Certeau a afirmar que o arquivo é uma memória expansionista, imunizada contra a alteridade (CERTEAU, 2005). O que muda, ao longo do tempo, é o valor, a relevância e o significado do arquivo: como os itens nele contidos são interpretados ou incorporados. Há vários mitos que acompanham o arquivo, como aquele que nos faz acreditar que ele não é mediado, no sentido de que os objetos nele contidos significam algo fora da 
própria moldura do arquivo, enquanto na realidade o que torna um objeto parte de um arquivo, isso é, documento, é o processo pelo qual é selecionado para a análise. Outro mito é de que o arquivo resiste às mudanças, à corruptibilidade e às manipulações de interesses políticos, mas verdade é que partes dele podem aparecer ou desaparecer conforme os interesses mais diversos. A equação escrita como memória/conhecimento é central para a epistemologia ocidental, como escreve Carruthers (2002, p.30): "La métaphore de la mémoire comme surface écrite est si ancienne et si constante dans toutes les cultures d' Occident qu'il faut y voir, je crois, un modèle directeur ou [...] um arquétype cognitif".

Embora a apropriação, a reprodução e o reprocessamento sejam práticas possíveis graças aos dispositivos técnicos e de registro de imagens, o gatilho que levou os artistas a usarem técnicas temporais ligadas aos princípios do arquivo foi o entendimento da obra como processo, surgido nos anos 1960. Desde então, uma das bases poéticas da produção artística tem sido a constituição de acontecimentos que, inseridos na vida, potencializam a existência diante de suas várias dimensões: material, política, cultural, individual etc. Dito de outra maneira, o tempo real da experiência da obra se tornou uma das estratégias bem presentes nas práticas artísticas. As questões em jogo se afastaram da representação ilusionista para examinar a produção de modos diferenciados de vida que tornam mais potente a existência real das ações e se constituam em rupturas no presente vivido: o foco da estratégia artística tornou-se o inventário de um arquivo que articula o fator temporal. A documentação artística possui uma força poética que cria seus próprios valores. Assim, desde as últimas décadas do século passado, arquivos digitais e materiais, instalações documentárias e imagens em séries, como em um arquivo, vêm constituindo novas linguagens poéticas para os artistas.

Sobre esse tema escreve Cristina Baldacci em seu Archivi Impossibili: un'ossessione dell'arte contemporanea (Arquivos impossíveis: uma obsessão da arte contemporânea seria uma tradução do título em português), publicado no final de 2016 pela editora Johan \& Levi, especializada em publicações ligadas aos museus e às práticas - também profissionais - que os envolvem.

A autora trabalha há vários anos sobre o tema da relação do arquivo com a arte, tanto de um ponto de vista histórico, bem como de crítica de arte, discutindo o papel, as formas e os sentidos que esse termo tem adquirido nas práticas artísticas contemporâneas. Porém, isso não seria suficiente a explicar a relevância desse tema no âmbito da Ciência da Informação, se não fosse a questão das transformações que a própria constituição dos arquivos enfrenta ao longo 
do século $\mathrm{XX}$, após a queda das certezas positivistas em sua organização e veracidade como "espelho" de sua entidade produtora. É isso que a autora discute na primeira parte do livro: em que medida se assiste a uma ampliação de sentidos quando se fala de arquivo, quando se observam agrupamentos organizados de memória e se escolhe defini-los pelo termo arquivo, ainda que esse termo apontasse para tipologias específicas de conjuntos de documentos (de fato, aqueles produzidos com as finalidades práticas da administração de uma entidade, aqueles que adquirem um valor jurídico).

O livro, a nosso ver, propõe algumas questões relevantes para a reflexão sobre os arquivos hoje: pode o registro ser pensado para além da simples documentação que ele efetiva na ordem simbólica? Pode ele ultrapassar a função social de prova da existência de algo que passou e com o qual se envolveu por contato direto? O registro possui a força para se tornar potência da obra?

Duas são as linhas de abordagem seguidas pelo livro: uma que levanta mais diretamente os problemas teóricos e históricos das noções de registro, de arquivo e de documento, e outra que se dirige às questões das práticas artísticas que utilizam esses arquivos. Uma divisão artificial, pois o que se encena é, aparentemente, que nenhuma classificação resiste à potência labiríntica que a corrói de dentro.

Com base nessa tensão, nesse aparente dualismo, a autora propõe um itinerário que convida a refletir sobre o arquivo enquanto "meio que permite realizar novas visões e construções do mundo, que nascem, frequentemente, em paralelo ou até antes do que o discurso filosófico-especulativo que pelo arquivo parece ser a cada dia mais fascinado" (BALDACCI, 2016, p. 9). Colecionar e arquivar, afirma a autora, tornaram-se gestos fundamentais para os artistas pelo menos desde Marcel Duchemp e o readymade, isso é, desde que o gesto de apresentar tomou o lugar do representar.

No livro, o percurso que busca seguir as inquietações apresentadas se desenrola ao longo das três partes que o compõem, dedicadas a primeira ao interesse pelos arquivos tanto de um ponto de vista teórico como de desenvolvimento artístico capaz de ilustrar essas reflexões (Archiviomania), a segunda às suas práticas (Pratiche d'archivio), em que um conjunto de artista é proposto como exemplar no cotejamento entre o trabalho do arquivista profissional em seu ambiente e a transposição desse trabalho na experiência artística e a terceira é dedicada à proposição do arquivo enquanto metáfora da memória. Nessa última parte, a autora ilustra artistas que subvertem, através de seus sistemas, os próprios critérios de classificação dos 
conhecimentos aos quais atribuímos valor, e disso decorre a escolha de titular o capítulo Anarchivi, Antiarchivi e Controarchivi.

Um primeiro capítulo, mais teórico, associa de maneira bastante clara as proposições possíveis sobre o arquivo, dialogando com Malraux, Foucault e Derrida, mas também com Burckhard, Benjamin e Warburg, os três vistos como essenciais para acessar as práticas de arquivo propostas pelos artistas, mas que, também, oferecem a possibilidade de arquivos mais tradicionais encaminhar suas reflexões com base em análises realizadas em campos de indagação diferentes dos costumeiros. Muitos são os artistas apresentados, dentre os quais ganham destaque Gerhard Richter, Gabriel Orozco, Marcel Broodthaers, Hans Haacke, através de análises que observam as práticas de inventariar, classificar, medir as várias facetas da realidade ou, por outro lado, os arquivos digitais onde não existe mais a materialidade e a solidez do arquivo se torna liquidez da informação e a questão que os artistas apresentam é ligada ao acesso, mas também ao excesso e à perda de orientação e, nisso, da própria memória.

Interessa, aqui, apontar algumas reflexões que o livro traz, ligadas ao que Hal Forster (2004) chama de arquival impulse, que teria suas raízes nas enciclopédias iluministas, nas taxonomias científicas e nas árvores do conhecimento produzidos no século XVII, bem como nos teatros da memória e nas wunderkammern, volando até os florilégios e os compêndios medievais. O quadro que Baldacci traça é de um interesse pelo arquivo no âmbito visual que abrange as vanguardas artísticas, sim, mas de maneira concomitante à construção do atlas Mnemosyne de Aby Warburg, imenso arquivo de imagens do qual se constitui ampla parte da cultura visual e das práticas dos artistas contemporâneos. Através dessa reconstituição histórica, Baldacci mostra o caminho pelo qual, entre as duas guerras mundiais, os artistas procuram caminhos contra a perda da memória, ilustrando as obras de August Sander e de Hanna Höch. O primeiro é autor de um arquivo fotográfico que retrata homens do século XX classificados por profissão, a segunda recolhe recortes de jornais em 1933 para ilustrar a vida na Alemanha da República de Weimar. Em ambos os artistas a autora observa a presença de um olhar multiétnico que, com a ascensão do nazismo, será perdido.

Destaque para o arquivo é apontado por Baldacci nas décadas de 1960 e 1970, com o aparecimento de novas tecnologias que iniciam o processo de desmaterialização da arte e a mesma se torna cada vez mais conceitual e, como observado acima, o olhar se concentra nos

processos. É nesse contexto que o aparente dualismo acima mencionado se torna mais presente, entre o ato de documentar ações, gestos e performances, e em várias ocasiões, no livro, é 
explicita a relevância atribuída a Harald Szeemann, o curador que, já na ocasião da exposição When Attitudes Become Form (1969), se destaca por ter sido o primeiro a buscar uma forma de catalogar as novas linguagens da arte.

Um dos artistas que se destaca nessa época é Edward Ruscha, cujas fotografias foram tiradas para serem "expostas" em livros manuseáveis, em que o registro é tomado como possibilidade documental, ou seja: o artista atualiza não o mimetismo do mundo, mas um ato reflexivo e crítico a respeito dele. O projeto fotográfico de Ruscha, de fato, não se limita a documentar a transformação urbana de Los Angeles. De 1962 a 1979 o artista publicou 17 livros compostos, em sua maioria, por fotografias em preto e branco, trabalhos que refletem o desejo de tornar a arte disponível ao grande público, barateando os custos dos próprios livros. Nestas publicações não somente o artista se utiliza de uma prática documental para ilustrar a transformação da cidade, mas sua experiência artística obriga a repensar a própria organização dos conhecimentos. De fato, misturando também os meios da arte e da literatura, coloca em cheque o sistema de organização das bibliotecas, para os quais continua difícil a inclusão dos livros “de artista". O livro não tem, em geral essa natureza artística, a não ser em relação ao conteúdo ou a algumas características editoriais que o tornam particularmente precioso. Os livros de Ruscha pertencem ao gênero livros de artista, mas sua incorporação nas bibliotecas tem provocado vários incidentes, pois suas classificações se basearam na natureza do objeto livro e não na identidade do artista, como observa Crimp (2005), explicando a presença do livro Twentysix Gasoline Stations na seção dedicada aos transportes na Biblioteca Pública de Nova York.

Grande destaque é dado à obra Atlas de Gerhard Richter, um atlas visual composto por mais de oito mil fotografias colecionadas e produzidas pelo artista a partir de 1962, que não representa unicamente os modelos iconográficos utilizados por ele, mas uma cartografia de seu pensamento e de sua vida entre o particular e o coletivo. Richter é exemplar em vários sentidos pelas práticas de arquivamento. Não somente expõem o arquivo enquanto obra de arte, ele exerce também um controle de suas entrevistas e de outros materiais que o envolvem, materiais publicados sob sua atenta supervisão, apontando a relevância do arquivo no controle de sua produção (portanto, sobre o mercado), traduzida no esforço de participar na produção do catálogo raissonne de suas obras, catálogo muito cuidadoso, produzido tanto em vários volumes impressos, como em versão online. 
O livro de Baldacci, enfim, se ocupa dos arquivos como pensados pela arte e pelos artistas, com uma sólida base teórica que permite trocas de experiência entre disciplinas diversas, o campo da arte e o campo da ciência da informação, lá onde a configuração do arquivo se torna visível em suas transformações que respondem à definição que de arquivos é dada por Foucault, através da síntese de Deleuze de que um arquivo "é o álbum audiovisual de uma época, o visível e o enunciável, que pode ser chamada formação histórica" (DELEUZE, 2014, p. 41).

\section{Referências}

CARRUTHERS, M. La livre de la mémoire: la mémoire dans la culture médiévale. Paris; Macula, 2002.

CERTEAU, M. La scrittura dell'altro. Milano; Raffaello Cortina, 2005.

CRIMP, D. Sobre as ruínas do museu. São Paulo; Martins Fontes, 2005.

DELEUZE, G. Il sapere: corso su Michel Foucault. Verona; Ombre Corte, 2014.

FORSTER, H. “An Archival impulse”. October, v. 110, p. 3-22, fall 2004. 